Chapman University

Chapman University Digital Commons

ESI Publications

Economic Science Institute

$4-2014$

\title{
Why Real Leisure Really Matters: Incentive Effects on Real Effort in the Laboratory
}

Brice Corgnet

Chapman University, corgnet@chapman.edu

Roberto Hérnan-Gonzalez

Eric Schniter

Chapman University, schniter@chapman.edu

Follow this and additional works at: http://digitalcommons.chapman.edu/esi_pubs

Part of the Business Commons, and the Economic Theory Commons

\section{Recommended Citation}

Corgnet, Brice, Roberto Hernán-González, and Eric Schniter. "Why real leisure really matters: Incentive effects on real effort in the laboratory." Experimental Economics (2014): 1-18.

DOI:10.1007/s10683-014-9401-4

This Article is brought to you for free and open access by the Economic Science Institute at Chapman University Digital Commons. It has been accepted for inclusion in ESI Publications by an authorized administrator of Chapman University Digital Commons. For more information, please contact laughtin@chapman.edu. 


\section{Why Real Leisure Really Matters: Incentive Effects on Real Effort in the Laboratory}

\section{Comments}

This is a pre-copy-editing, author-produced PDF of an article accepted for publication in Experimental

Economics in April 2014. The final publication is available at Springer via DOI: 10.1007/s10683-014-9401-4.

\section{Copyright}

Springer 


\section{Why Real Leisure Really Matters: \\ Incentive Effects on Real Effort in the Laboratory.}

Brice Corgnet, $\mathrm{PhD}$

Argyros School of Business and Economics, Chapman University

Economic Science Institute, Chapman University

One University Drive, Orange, CA, 92866

corgnet@chapman.edu

Phone: 714-744-7859

Roberto Hernán-González, PhD

Economics Department, University of Granada

Campus Universitario de La Cartuja 18071 Granada, Spain

roberto.hernangonzalez@gmail.com

Phone: (+34) 958-241-000

Eric Schniter, $\mathrm{PhD}$

Economic Science Institute, Chapman University

One University Drive, Orange, CA, 92866

eschniter@gmail.com

Phone: 714-628-7272 


\title{
Why Real Leisure Really Matters: Incentive Effects on Real Effort in the Laboratory.
}

\begin{abstract}
On-the-job leisure is a pervasive feature of the modern workplace. We studied its impact on work performance in a laboratory experiment by either allowing or restricting Internet access. We used a $2 \times 2$ experimental design in which subjects completing real-effort work tasks could earn cash according to either individual- or team-production incentive schemes. Under team pay, production levels were significantly lower when Internet browsing was available than when it was not. Under individual pay, however, no differences in production levels were observed between the treatment in which Internet was available and the treatment in which it was not. In line with standard incentive theory, individual pay outperformed team pay across all periods of the experiment when Internet browsing was available. This was not the case, however, when Internet browsing was unavailable. These results demonstrate that the integration of on-the-job leisure activities into an experimental labor design is crucial for uncovering incentive effects.
\end{abstract}

KEYWORDS: Incentive, Free riding, Internet access, Experimental method JEL CODES: C92, D23, M52 


\section{INTRODUCTION}

\section{Studying Incentives in the Lab}

Incentive theory plays a crucial role in the study of economic phenomena and is a natural candidate for extensive experimental investigation. As a result, the field of experimental labor economics (Charness and Kuhn, 2011) has emerged to test many of the predictions that have been generated by incentive and contract theories (Laffont and Martimort, 2002; Bolton and Dewatripont, 2005). These experimental protocols have, however, left aside the study of on-thejob leisure activities which unarguably constitute an important part of the work environment (Malachowski, 2005). In this paper, we propose to fill this gap by integrating on-the-job leisure into the evaluation of incentive effects in the laboratory.

From a methodological standpoint, the inclusion of on-the-job leisure activities in laboratory experiments may help attenuate active participation, an issue raised by Lei, Noussair and Plott (2001) in the context of experimental asset markets. Specific details of an experiment protocol, such as availability of alternatives to focal "work", might encourage or fail to encourage subjects to actively perform effortful work. For example, subjects may engage actively in a focal work task because of expectations, rewards, and lack of desirable alternatives. When desirable alternatives are present, active participation in effortful work may be traded off to some degree, revealing subtle incentive effects such as from small shifts in wage or manipulations of incentive schemes. We suspect that active participation has previously been an issue because, despite predictions that individual incentives should outperform team incentives (Alchian and Demsetz, 1972; Holmström, 1982), several published studies, and perhaps even more unpublished studies, have failed to observe such differences (van Dijk, Sonnemans and van Winden, 2001; Dohmen and Falk, 2011).

\section{The Real-Leisure Alternative}

We investigated the effects of providing a leisure alternative on subjects' performance in a real-effort work task by either allowing or restricting Internet access during the experiment. We considered a real-effort mental arithmetic (summation) task in the spirit of previous laboratory experiments (Niederle and Vesterlund, 2007; Bartling, Fehr, Maréchal and Schunk, 2009; Eriksson, Poulsen and Villeval, 2009; Dohmen and Falk, 2011). ${ }^{1}$ We manipulated the incentive

\footnotetext{
${ }^{1}$ A large number of studies have incorporated other types of real-effort tasks such as solving mazes (Gneezy, Niederle and Rustichini, 2003), puzzles (Rutström and Williams, 2000), anagrams (Charness and Villeval, 2009),
} 
setting by rewarding work performance according to either an individual pay or team pay scheme.

We used Internet browsing to represent on-the-job "real-leisure" 2 because it is a growing and popular on-the-job leisure activity and a representative feature of the workplace. The availability of on-the-job Internet access has increased, due in part to most Americans now owning a smartphone capable of Internet browsing and less subject to employee usage restrictions (Smith, 2013). According to a 2005 study by American Online and Salary.com, employees spent about $26 \%$ of their time on activities unrelated to their work (Malachowski, 2005). Almost half of this time was spent browsing the Internet. Also, the Internet is frequently browsed by and widely available to university students (our subject pool), providing them with a wide range of activities (Jones et al., 2009).

Previous studies have proposed alternative experimental designs to moderate active participation in experiments. For example, Mohnen, Pokorny and Sliwka (2008) gave subjects the option to take a 25 -second time-out during which they were not able to work on the counting task and for which they were paid $0.10 €$. While subjects frequently engage in pleasurable activity during their breaks (e.g. socializing, browsing the Internet), the time-out setting investigated by Mohnen and colleagues rewarded subjects for taking breaks characterized by inactivity. Contrary to these designs with "abstract" leisure, in our environment we expect heterogeneity in derived utility from leisure (here proxied by internet access). However, Internet browsing, by offering an unprecedented range of leisure options, reduces the heterogeneity in the value of leisure compared to other "real leisure" alternatives such as giving subjects access to selected magazines. Also, the advantage of this implementation is that subjects can choose to engage in leisure activity - a more representative feature of the real workplace.

In line with the real-effort literature we argue that a real-leisure option cannot be instantiated simply as a decision for a monetary alternative. For example, workers who may be reluctant to steal money from an employer or firm may still be willing to spend time browsing

optimization problems (Dickinson and Villeval, 2008; Montmarquette et al., 2004; van Dijk, Sonnemans and van Winden, 2001), typing (Dickinson, 1999) or mailing tasks (Carpenter, Matthews and Schirm, 2010; Falk and Ichino, 2006).

${ }^{2}$ Evidence from neuroscience supports an association between rewarding Internet activities and dopamine (Koepp et al., 1998; Tamir \& Mitchell, 2012), supporting the notion that Internet browsing is a "real", not abstract, form of leisure. Furthermore, dopamine levels across different parts of the brain have been shown to influence one's work ethic (Treadway et al., 2012), suggesting the mechanism by which real-leisure alternatives may interfere with realeffort. 
the Internet while paid for being "on-the-job". They may justify Internet browsing as part of their legitimate search for valuable work information or they may consider paid work to include some real-leisure "breaks". Internet browsing on the job has been shown to damage employees' productivity (Young, 2005; 2006) and incurred U.S. corporations at least $\$ 85$ billion in yearly costs (Alder, Noel and Ambrose, 2006). Consideration of leisure-related issues in the experimental economics literature dates back to Dickinson's (1999) labor supply study in which subjects working on a typing task were provided an option to leave the laboratory whenever they had achieved a certain output level. Quitting options have since been introduced into subsequent studies on minimum wages and workfare (e.g. Falk and Huffman, 2007, Abeler et al., 2011). Given the lack of control over subjects' activities and desired alternatives outside the laboratory, heterogeneity in quitting behaviors has been difficult to interpret. Quitting options are also not representative of the typical workplace regime as salaried employees in most organizations are required to comply with a minimum number of completed work hours per pay period.

Unlike previous experiments, our design embeds on-the-job leisure alternatives into the work environment, allowing the measurement of each subject's time allocation to leisure or work activities. While two related experimental studies (Eriksson, Poulsen and Villeval, 2009; Charness, Masclet and Villeval, 2010) have introduced on-the-job leisure alternatives by giving subjects access to magazines (for browsing or reading), they have not reported effects of on-thejob leisure activity on subjects' performance. $^{3}$

To our knowledge, ours is the first experimental work to have measured subjects' time allocation to real-effort work tasks or on-the-job leisure and to have analyzed the effects of access to leisure on subjects' performance. We studied the effect of on-the-job leisure in two of the most popular incentive schemes: individual pay and team pay (e.g. Prendergast, 1999; Lazear, 2000; Hamilton, Nickerson and Owan, 2003). We conducted a $2 \times 2$ design in which we varied the availability of Internet access (available or not) and the type of pay (rewarded according to individual performance or team performance). For each of the four treatments, subjects were matched in groups of seven to ten people and completed the experiments in five periods of 20 minutes.

\footnotetext{
${ }^{3}$ Since Deci (1971), experiments measuring motivation have also provided subjects access to magazines during experiments as a real leisure alternative to a focal task (though they do not measure and report time allocated to browsing magazines). The provision of magazines while measuring "free choice intrinsic motivation" is still reported in more recent psychology and decision science publications (e.g. Zapata-Phelan, Colquitt, Scott, \& Livingston, 2009).
} 
Subjects used the Internet option when available. They dedicated $28.5 \%$ of their time to browsing the Internet under team pay while only dedicating $11.9 \%$ of their time to Internet browsing under individual pay. Consequently, the impact of Internet browsing on subjects' performance was different across payment schemes. The availability of Internet browsing reduced production significantly under team pay while it did not reduce production under individual pay. In addition, we observed that incentive effects (measured as the difference in production between the individual pay and the team pay treatments) were more pervasive when Internet browsing was available. In the presence of Internet browsing, incentive effects were significant across all periods of the experiment while no incentive effects were found in the first two periods of the experiment when Internet browsing was not included in the design. This suggests that incentive effects may be sensitive to real-leisure alternatives such as Internet browsing and that previous real-effort experiments lacking this feature may have failed to uncover incentive effects which are reasonable to expect in the workplace.

\section{EXPERIMENTAL ENVIRONMENT}

We developed a framework in which subjects could undertake a real-effort task, while being able to browse the Internet. ${ }^{4}$

\section{The Work Task}

Adapted from previous research using mental arithmetic (summation) tasks (e.g., Eriksson, Poulsen and Villeval, 2009), the work task required real-effort in the form of mental concentration (because it makes strong demands on working memory (see Chase and Ericsson, 1982)). By using a long, repetitive and effortful task we ensured that individual performance was mostly driven by real (mental) effort considerations. The duration of our task, 5 periods of 20 minutes each, as well as its intricacy were considerably greater than in previous real-effort experiments that have reported the use of summation tasks (Niederle and Vesterlund, 2007; Bartling, Fehr, Maréchal and Schunk, 2009; Eriksson, Poulsen and Villeval, 2009; Dohmen and Falk, 2011). The task required subjects to sum up tables of 36 numbers without using a pen, scratch paper, or calculator (see Figure 1). Each table had six rows and six columns of randomlygenerated numbers from zero to ten. Before providing the grand total in the bottom-right cell, subjects had to provide separate subtotals for each of the 12 rows and columns. Calculating these

\footnotetext{
${ }^{4} \mathrm{~A}$ video presentation of the software is available at: https://sites.google.com/site/realleisureincentives/home/video.
} 
subtotals did not directly generate earnings but could help subjects compute the grand total. A correct grand total answer increased production by 40 cents while 20 cents were subtracted if the answer was incorrect..$^{5}$ After completing each table, subjects learned whether their answer was correct and what their accumulated production value was. At the end of each period, subjects learned the total amount of money generated on the work task by all subjects of their group.

Figure 1. - WORK TASK.

\begin{tabular}{|c|c|c|c|c|c|c|c|}
\hline & Column1 & Column2 & Column 3 & Column4 & Column5 & Column6 & Sum Row \\
\hline & 3.00 & 6.00 & 3.00 & 0.00 & 6.00 & 0.00 & \\
\hline & 10.00 & 5.00 & 1.00 & 5.00 & 2.00 & 3.00 & \\
\hline & 8.00 & 3.00 & 5.00 & 4.00 & 8.00 & 7.00 & \\
\hline & 1.00 & 6.00 & 0.00 & 9.00 & 8.00 & 0.00 & \\
\hline & 3.00 & 7.00 & 0.00 & 8.00 & 10.00 & 4.00 & \\
\hline & 3.00 & 10.00 & 10.00 & 6.00 & 10.00 & 0.00 & \\
\hline Sum Column: & & & & & & & \\
\hline
\end{tabular}

At any point during the experiment, all subjects in the treatments with Internet availability could switch from the work task to Internet browsing, and vice versa. Subjects could spend as much or as little time as they wanted on the various activities, each of which was undertaken on a separate screen. To switch activities, subjects simply chose the corresponding option from a drop-down menu at the bottom-right of their screens.

\section{Internet Browsing}

In the "Internet" treatments where the leisure alternative was available, if subjects chose to browse the Internet, the work task window was replaced by an Internet window (embedded in the software; see Figure 2). Within the bounds of university policy, subjects could use the Internet however they liked, including email, instant messaging, and social networking. Their confidentiality was assured and maintained, but the software tracked the exact amount of time spent on each activity. Subjects did not receive feedback regarding others' use of the Internet. Although subjects could not complete the work task while browsing the Internet, switching between tasks was quick and easy. Subjects were told in the instructions that using any internetbased devices, or calculators, to sum up numbers was not allowed.

\footnotetext{
${ }^{5}$ So that subjects did not lose money for their participation, penalties only applied when individuals had already produced a positive amount.
} 


\section{Figure 2. - EMBEDDED INTERNET SCREEN.}

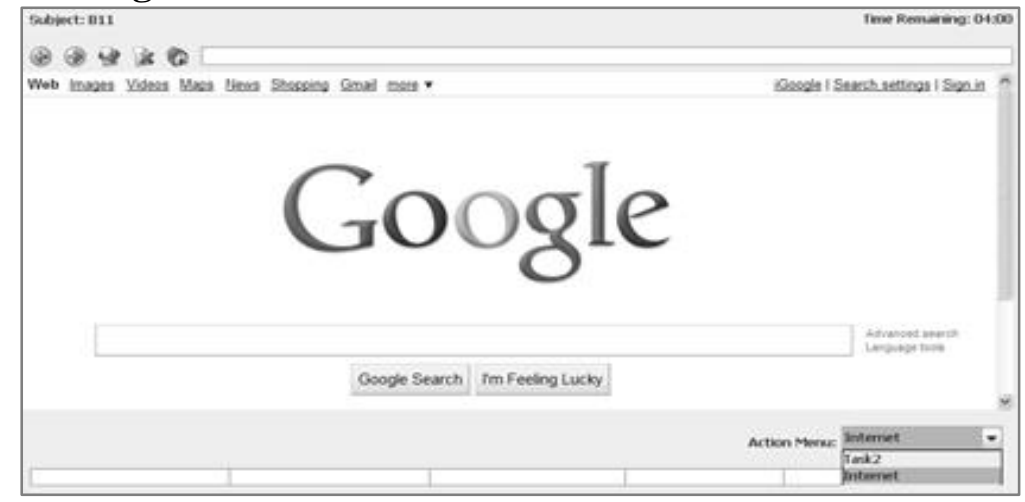

\section{Click Pay}

In addition to the activities described above, subjects could click on a yellow box that appeared at the bottom of their screen every 25 seconds, independent of whether the subject was currently working on the task or browsing the Internet. Each time subjects clicked on the yellow box they earned 5 cents. The earnings on this task were intended to represent a fixed wage of $\$ 12$ which was paid in addition to the performance pay.

\section{TREATMENTS, HYPOTHESES AND PROCEDURES}

\section{Treatments}

We conducted four treatments as part of a $2 \times 2$ design in which we varied the availability of the Internet ("Internet" or "No Internet") and the type of performance-based incentive scheme ("individual pay" or "team pay"). In the individual pay treatments, subjects were rewarded on the work task according to their individual production. Under team pay, the total production of the group was equally distributed among subjects so that each of them received $10 \%$ of the total production of the 10 group members in each session.

\section{Hypotheses}

We derive our hypotheses from the moral-hazard in teams model introduced by Holmström (1982). We consider $N$ workers producing a total output $f e_{1}, e_{2}, \ldots, e_{N}$ which depends on each worker's effort $e_{i}$ where $i \in 1, \ldots, N$. Each worker $i$ decides to allocate her time, normalized to one, to the following activities: work effort $\left(e_{i} \geq 0\right)$ or leisure $\left(l_{i} \geq 0\right)$, so that $e_{i}+l_{i} \leq 1$. The utility function of worker $i$ can be expressed as follows:

$$
U_{i}:=s_{i} f e_{i} ; e_{j}, \ldots, e_{N}-C e_{i}+\eta l_{i}
$$


where $C e_{i}$ stands for the cost of effort function with $C^{\prime}>0$ and $C^{\prime \prime}>0, \eta l_{i}$ stands for the utility of leisure with $\eta^{\prime}>0$ and $\eta^{\prime \prime}<0$, and $s_{i}$ stands for the share of group production assigned to worker $i$. Under team pay, $s_{i}=\frac{1}{N}$ while under individual pay workers are rewarded according to their actual contribution to the group outcome. If we assume that $f$ is separable in workers' effort and in particular if we assume that $f e_{i} ; e_{j}, \ldots, e_{N}=A{ }_{k=1}^{N} e_{k}$, where A is the marginal product of effort, then $s_{i}=\frac{e_{i}}{N_{k=1} e_{k}}$ under individual incentives. ${ }^{6}$ We derive our main predictions by using the following specification of the workers' utility function: ${ }^{7}$

$$
U_{i}:=s_{i} A e_{k=1}^{N} e_{k}-\alpha \frac{e_{i}^{2}}{2}-\beta \frac{1-l_{i}^{2}}{2}
$$

where $\alpha>0$ and $\beta>0$. We obtain the following equilibrium values for work effort for individual pay with (without) Internet: $\min \frac{A}{\alpha+\beta}, 1\left(\min \frac{A}{\alpha}, 1\right)$ and for team pay with (without) Internet: $\min \frac{A}{N \alpha+\beta}, 1\left(\min \frac{A}{N \alpha}, 1\right) .^{8}$ We compare work effort, leisure (time spent browsing the Internet), and production across treatments and summarize our findings in the following hypotheses.

\section{Hypothesis 1 (Internet Availability Effects across Incentive Schemes)}

Under individual [team] pay, subjects are expected to produce less with the real-leisure option to browse the Internet than without it, provided $\alpha+\beta>A[N \alpha+\beta>A]$. Otherwise, for a given incentive scheme no difference in subjects' production is expected between the available and unavailable Internet treatments.

Therefore, if the cost of effort $\alpha$ and the utility of leisure $\beta$ are sufficiently high compared with the marginal productivity of effort $(A)$, Internet availability will reduce subjects' production. This condition is more likely to be satisfied under team pay since $N>1$. Additionally, the decrease in production due to Internet browsing should be more pervasive where the utility of leisure $(\beta)$ is greater.

\footnotetext{
${ }^{6}$ Kandel and Lazear (1992) assume nonseparability in effort so as to justify the existence of partnerships and eliminate the possibility of self-employment. In this paper, we do not aim at justifying the existence of partnerships and simply assume separability of the utility function in effort so as to match our experimental design more closely.

${ }^{7}$ For simplicity of exposition, we express the utility of leisure (Internet browsing) as the opportunity cost of not browsing the Internet $\left(1-l_{i}\right)$.

${ }^{8}$ We derive these calculations in Appendix A.
} 


\section{Hypothesis 2 (Incentive Scheme Effects and Internet Availability)}

When Internet is [not] available, subjects are expected to produce less with team pay than with individual pay, provided $N \alpha+\beta>A$ [N $\alpha>A]$. Otherwise, no difference in subjects' production is expected between incentive schemes.

Therefore, if the cost of effort and the utility of leisure are sufficiently high compared with the marginal productivity of effort, production should be higher under individual pay than under team pay. This condition is more likely to be satisfied when Internet is available since $\beta>0$. In addition, we show in Appendix A that in the case in which Internet is available the difference in production between individual pay and team pay increases in the utility of leisure and in the cost of effort if $\alpha+\beta \leq A$ and $N \alpha+\beta>A$, and decreases in both variables if $\alpha+\beta>A$.

\section{Procedures}

Two-hundred forty three individuals were recruited from a subject pool at a major U.S. university to participate in the current study in exchange for money. The experiments took place between December 2010 and May 2011 with treatments randomly assigned across 26 experiment sessions (see Table 1$)^{9}$

Table 1. - SUMMARY OF TREATMENTS.

\begin{tabular}{|c|c|c|c|}
\hline & & \multicolumn{2}{|c|}{ Real-Leisure Availability } \\
\hline & & No Internet & Internet \\
\hline \multirow{2}{*}{ Incentive Schemes } & Individual Pay & $7(57)$ & $7(66)$ \\
\hline & Team Pay & $6(60)$ & $6(60)$ \\
\hline
\end{tabular}

Subjects were told that the set of computerized instructions were identical for all the subjects. Subjects had 20 minutes to read the instructions (see Appendix C), with a timer displayed on a large screen at the front of the lab. ${ }^{11}$ Experimental sessions lasted on average two hours and thirty minutes.

At the end of the experiment, subjects were paid their earnings in cash, rounded up to the nearest quarter. Individual earnings at the end of the experiment were computed as the sum of

\footnotetext{
${ }^{9}$ Technical issues prevented the analysis of one of the sessions in the treatment with individual pay and no Internet.

${ }^{10}$ All sessions involved groups of ten subjects except two sessions with 8 subjects in the treatment with individual pay and Internet, and two sessions with 8 subjects and three sessions with 7 subjects in the treatment with individual pay and no Internet.

${ }^{11}$ None of the subject asked questions or requested extra time.
} 
the earnings in the five periods. Subjects earned on average \$26.94 (including the \$7 show-up fee).

\section{RESULTS}

\section{Aggregate measures}

We define production as the monetary amount generated by a subject's answers on the work task divided by the reward for each correct answer $(40 \phi)$. Production can thus be interpreted as the total number of correct tables completed by a given subject discounted by the (weighted) number of incorrect answers. In Table 2, we report descriptive statistics of subjects' total production from the work task in the five periods of the experiment, across treatments.

Table 2. - TOTAL PRODUCTION.

\begin{tabular}{|c|c|c|c|c|c|}
\hline \multicolumn{2}{|c|}{ Treatment } & Average & Median & $\begin{array}{l}\text { Standard } \\
\text { deviation }\end{array}$ & $\begin{array}{c}\text { Two-sided p-values } \\
\text { Clustered t-test } \\
\text { (Clustered Rank Sum test) }\end{array}$ \\
\hline Incentive & Internet & & & & \\
\hline Scheme & Availability & & & & \\
\hline \multirow{2}{*}{ Individual Pay } & No Internet & 24.60 & 23.50 & 12.19 & $p=.272$ \\
\hline & Internet & 22.16 & 22.00 & 11.86 & $(p=.118)$ \\
\hline \multirow{2}{*}{ Team Pay } & No Internet & 19.53 & 21.25 & 9.19 & $p=.035$ \\
\hline & Internet & 15.64 & 15.25 & 10.55 & $(p=.014)$ \\
\hline
\end{tabular}

Under team pay, subjects' total production was significantly lower in the treatment in which Internet was available than in the treatment in which it was not, whether we used parametric or non-parametric clustered tests. Clustered tests were used to control for the fact that individual production in a given session may have been affected by group production. ${ }^{12}$ These findings are in line with Hypothesis 1 according to which the availability of Internet reduces production under team pay as long as $N \alpha+\beta>A$. Under individual pay, even though average (median) production was $11.0 \%(6.8 \%)$ lower when Internet was available than when it was not, the difference was not statistically significant. This is consistent with our model when $\alpha+\beta \leq$ $A$, in which case the level of effort is maximal whether Internet is available or not. The fact that

\footnotetext{
12 This correction was especially relevant for the treatments with team pay in which case the contributions of other group members, displayed on a subject's screen at the end of each period, may have affected an individual's motivation to work. This may have led subjects to free ride whenever they observed an increase in group production as is the case in standard public good games (see Ledyard (1995) for a survey, and Corgnet et al. (2011) for further analyses).
} 
Internet effects were significant under team pay while they were not significant under individual pay relates to the fact that Internet usage was more pronounced under team pay $(28.5 \%$ of subjects' available time) than under individual pay (11.9\%) (Clustered t-test and rank-sum tests: $p<.001$ and $p=.008$, respectively).

Intensive Internet users produced significantly less than other subjects, regardless of the treatment, stressing the disruptive effect of using the Internet. In particular, the probability of completing a given table correctly was negatively affected by switching between the work task and the Internet and by time spent browsing (see Appendix D for the statistical analysis). Also, production levels were negatively correlated with the time subjects spent on the Internet. The correlation coefficients were equal to $-0.727(\mathrm{p}<0.001)$ and $-0.582(\mathrm{p}<0.001)$ under pay and individual pay, respectively. ${ }^{13}$

We summarize our findings as follows.

\section{RESULT 1. (Internet effects)}

Under team pay, subjects produced significantly less in the treatment in which Internet was available than in the treatment in which it was not. Under individual pay, the availability of Internet had no significant effect on subjects' production.

In the treatments in which Internet was available, subjects produced on average $41.7 \%$ more under individual pay than under team pay (Clustered t-test and rank-sum tests: $p=.001$ and $p=.005$, respectively). Similarly, in the absence of Internet subjects produced $25.9 \%$ more under individual pay than under team pay (Clustered t-test and rank-sum tests: $p=.012$ and $p=.014$, respectively). These findings are summarized below. ${ }^{14}$

RESULT 2. (Incentive effects)

Regardless of Internet availability, subjects produced significantly more under individual pay than under team pay.

\footnotetext{
${ }^{13}$ We find similar results using a panel regression of individual production with robust standard deviations for session clusters and controlling for a period trend, in which internet coefficients are negative and significant for both treatments (p's < 0.001).

${ }^{14}$ We confirm these findings in a difference-in-difference regression of total production with robust standard deviations for session clusters. We find that the coefficient for the Team Pay dummy is negative and significant $(\mathrm{p}=$ 0.002). However the Internet dummy and the interaction dummy, although negative, are not significant ( $\mathrm{p}=0.152$ and $\mathrm{p}=0.489)$.
} 
In addition to engaging in the work task and Internet browsing, subjects could obtain earnings from the low-effort clicking task. No significant differences in the clicking task earnings were observed across treatments (see Table B1 in Appendix B).

\section{Production dynamics}

We measured time allocations to Internet browsing and work effort over the five periods of our experiment to study the dynamics of production. The evolution of production is particularly relevant in our setting given that fatigue and boredom are likely to arise when completing the real-effort task repeatedly. Consistently, Internet usage surged from period three onwards (see Corgnet et al. 2011 for further analyses). Under individual (team) pay, subjects allocated 5.6\% (19.1\%) of their time to Internet browsing during the first two periods compared with $16.4 \%$ $(34.8 \%)$ during the last three periods. The increase in shirking (Internet use) over time under team pay is consistent with findings in public good games, in which contributions are found to decrease over time (see Ledyard (1995) for a survey). ${ }^{15} \mathrm{We}$ observed a positive trend in production for each of the four treatments (see Table B2 in Appendix B), consistent with learning effects in repeated mental calculation tasks noted in the literature (e.g. see Charness and Campbell, 1988). The dynamics of production differ, however, across treatments as is illustrated in Figure 3 below.

\section{Figure 3. - PERIOD EVOLUTION OF AVERAGE PRODUCTION FOR TREATMENTS WITH AND WITHOUT INTERNET ACCESS.}

The case of individual (team) pay is shown on the left (right) panel.

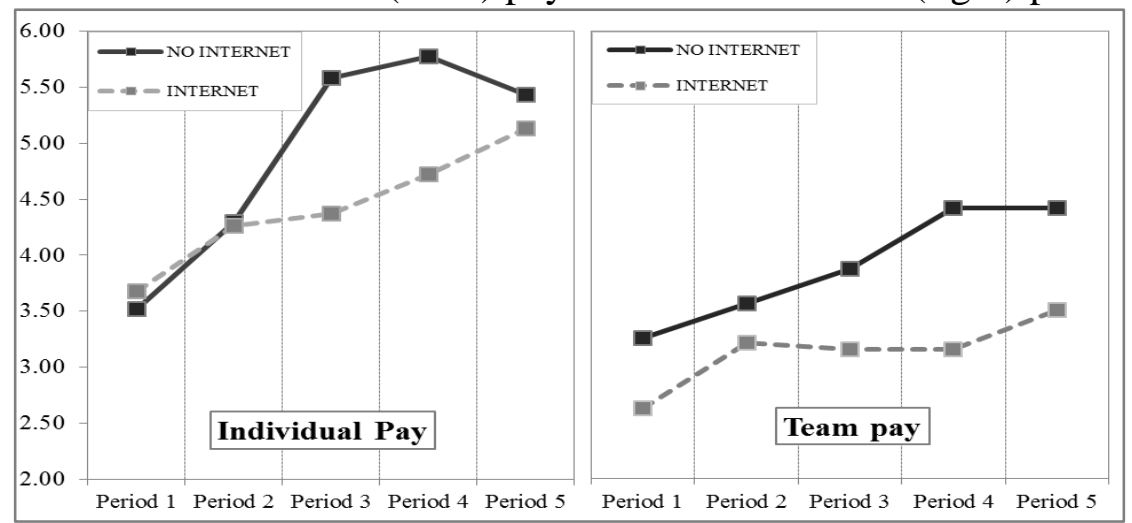

\footnotetext{
${ }^{15}$ In Corgnet et al. (2011), we show (see Table A.2, p5), similarly to the findings in public good games, that an increase in group production in a given period decreased the production of high performers (above the average group production) while increasing the production of low performers (below the average group production) in the next period.
} 
Under individual pay, the treatment in which Internet was available and the treatment in which it was not led to similar production levels in the first two periods. However, from period three onwards subjects produced relatively more in the treatment in which Internet was not available. A similar pattern of production was observed under team pay incentives (see right panel in Figure 3). These observations suggest that the effect of Internet availability is particularly pronounced after period 2, when Internet usage becomes more prevalent (see Figure 4 below).

Figure 4. - DYNAMICS OF INTERNET EFFECTS ACROSS INCENTIVE SCHEMES. The case of individual (team) pay is shown on the left (right) panel.
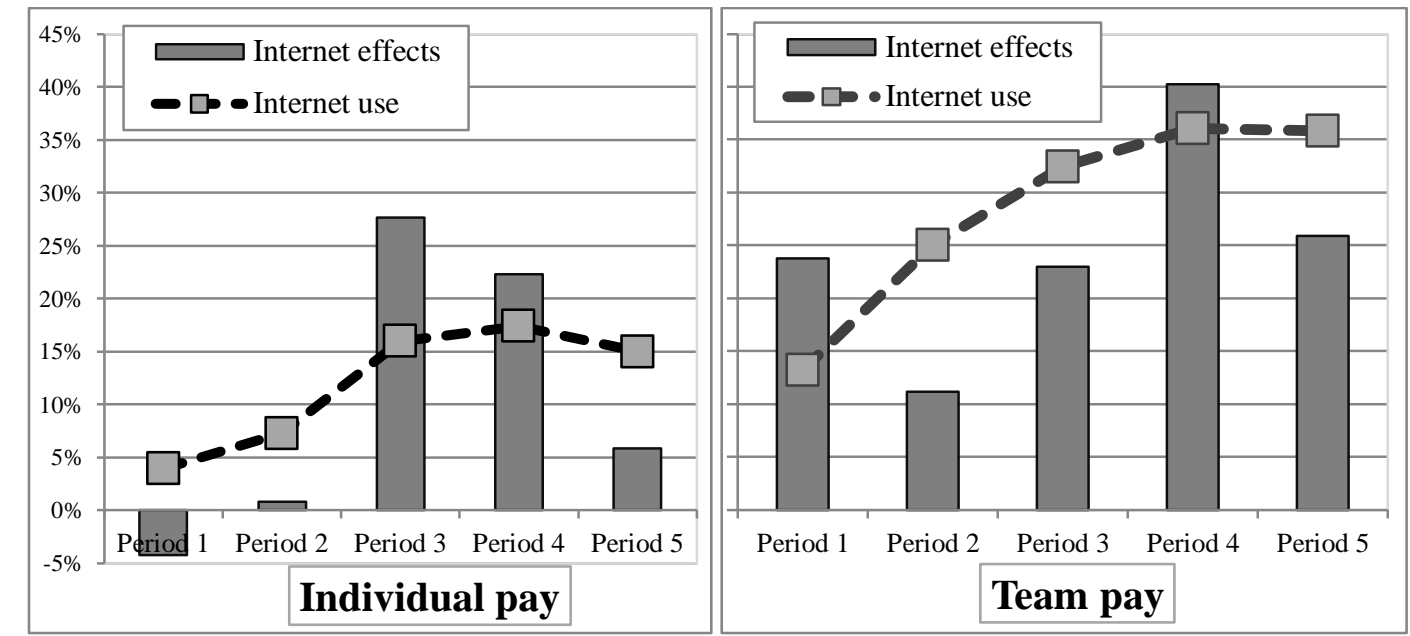

Internet effects are the difference in average production between Internet and No Internet treatments. Internet use is the percentage of time subjects spent browsing the Internet.

Consequently, we proceed by comparing the Internet and No Internet treatments in the first two periods of the experiment and in the last three periods separately, for each incentive scheme (see Table 3).

TABLE 3. - PRODUCTION DYNAMICS.

Panel regressions with random effects and robust standard deviations for session clusters.

\begin{tabular}{|c|c|c|c|c|c|c|c|c|}
\hline & \multicolumn{2}{|c|}{$\begin{array}{c}\text { INDIVIDUAL PAY } \\
\text { TREATMENTS }\end{array}$} & \multicolumn{2}{|c|}{$\begin{array}{c}\text { TEAM PAY } \\
\text { TREATMENTS }\end{array}$} & \multicolumn{2}{|c|}{$\begin{array}{l}\text { NO INTERNET } \\
\text { TREATMENTS }\end{array}$} & \multicolumn{2}{|c|}{$\begin{array}{c}\text { INTERNET } \\
\text { TREATMENTS }\end{array}$} \\
\hline & $\begin{array}{l}\text { Periods } \\
1 \& 2 \\
\end{array}$ & $\begin{array}{l}\text { Periods } \\
3 \text { to } 5\end{array}$ & $\begin{array}{c}\text { Periods } \\
1 \& 2 \\
\end{array}$ & $\begin{array}{l}\text { Periods } \\
3 \text { to } 5 \\
\end{array}$ & $\begin{array}{l}\text { Periods } \\
1 \& 2\end{array}$ & $\begin{array}{c}\text { Periods } \\
3 \text { to } 5 \\
\end{array}$ & $\begin{array}{c}\text { Periods } \\
1 \& 2 \\
\end{array}$ & $\begin{array}{l}\text { Periods } \\
3 \text { to } 5 \\
\end{array}$ \\
\hline Intercept & $2.89 * * *$ & $4.92 * * *$ & $2.73 * * *$ & $3.34 * * *$ & $3.09 * * *$ & $5.18 * * *$ & $3.09 * * *$ & $3.60 * * *$ \\
\hline $\begin{array}{l}\text { Period } \\
\text { Trend }\end{array}$ & $.68 * * *$ & .17 & $.45^{* *}$ & $.23 * * *$ & $.54 * * *$ & .10 & $.59 * * *$ & $.28 * * *$ \\
\hline $\begin{array}{l}\text { Dummy } \\
\text { Internet }\end{array}$ & .06 & $-.85 * *$ & $-.49 * * *$ & $-.97 * * *$ & - & - & - & - \\
\hline $\begin{array}{l}\text { Dummy } \\
\text { Team Pay }\end{array}$ & - & - & - & - & -.50 & $-1.36 * * *$ & $-1.05 * * *$ & $-1.47 * * *$ \\
\hline
\end{tabular}

$* \mathrm{p}$-value<.10, ** $\mathrm{p}$-value<.05, and $* * * \mathrm{p}$-value<.01.

Dummy Internet takes value 1 if the treatment allows for internet browsing, and value 0 otherwise.

Dummy Team Pay takes value 1 if subjects were rewarded with team pay, and value 0 if they were rewarded with individual pay. 
Under individual pay, the negative effect of Internet browsing was significant in the second part of the experiment while it was not in the first part of the experiment (see Dummy Internet in Table 3). This finding suggests that the effect of introducing a real-leisure alternative to the work task is likely to be more pronounced when the work task is sufficiently long. In our model, Internet browsing does not impact production whenever the cost of effort is low enough $(\alpha+$ $\beta \leq A)$ since then subjects exert maximal effort regardless of Internet availability. However, as fatigue emerges in the second part of the experiment, the cost of effort is likely to rise which may imply that $\alpha+\beta>A$. In that case, our model predicts that Internet browsing will affect production negatively in line with our empirical findings. In the case of team pay and unlike the case of individual pay, the negative effect of Internet availability was observed across all periods of the experiment. The fact that internet effects were observed in the first part of the experiment under team pay while they failed to be observed under individual pay is consistent with our model as long as $\alpha+\beta \leq A$ and $N \alpha+\beta>A$. We summarize our findings in Result 3 .

RESULT 3. (Internet effects are dynamic)

i) Under team pay, in all periods, subjects produced significantly less in the treatment in which Internet was available than in the treatment in which it was not.

ii) Under individual pay, during the first two periods, subjects produced similarly in the treatment in which Internet was available and in the treatment in which it was not. During the last three periods, subjects produced significantly less in the treatment in which Internet was available than in the treatment in which it was not.

Regarding incentive effects, significant differences in production levels between individual and team pay were only observed in the second part of the experiment in the case in which Internet was not available (see Dummy Team Pay for no Internet Treatments in Table 3). In the case in which Internet was available, however, production was significantly higher under individual pay than under team pay across all periods of the experiment (see Dummy Team Pay for Internet Treatments in Table 3). As a result, in the presence of a real-leisure alternative to the work task, incentive effects are more likely to be detected in shorter and less effortful experiments where they might not be otherwise. We summarize this in Result 4. 
RESULT 4. (Incentive effects are dynamic)

i) In the first two periods, subjects produced similarly under team pay and individual pay in the case in which Internet was not available. Subjects produced significantly more under individual pay than under team pay, however, in the case in which Internet was available.

ii) In the last three periods, subjects produced significantly more under individual pay than under team pay regardless of Internet availability.

\section{CONCLUSIONS}

Studying incentives in the laboratory is a fundamental yet challenging endeavor. We contribute to the experimental labor economics literature by assessing how a real-leisure alternative (Internet browsing) interacts with manipulated incentives. We incorporated on-the-job leisure in the experimental protocol by either allowing or restricting Internet access in an experimental workplace. We showed that subjects dedicated time to this leisure activity when available, suggesting that part of the performance observed in labor experiments without realleisure can be explained by the lack of alternative desirable activities. Importantly, we identified that the availability of Internet browsing did not have the same impact under different payment schemes. Under the weaker incentive scheme (team pay), Internet browsing was more prevalent than under the stronger incentive scheme (individual pay). As a result, incentive effects which were measured as the difference in production levels between the individual and the team pay treatments were more pervasive when Internet browsing was available. Our findings suggest that researchers conducting laboratory experiments without real-leisure alternatives may be operating under the hazard of unattenuated active participation, a condition that does not accurately model incentive tradeoffs between effortful tasks and leisure tasks and which might underestimate effects of incentive manipulation that really matter in the workplace. 


\section{REFERENCES}

Abeler, J., Falk, A., Goette, L., \& Huffman, D. (2011). Reference points and effort provision. The American Economic Review, 101(2), 470-492.

Alder, G., Noel, T., and M. Ambrose (2006): "Clarifying the Effects of Internet Monitoring on Job Attitudes: The Mediating Role of Employee Trust," Information and Management, 43(7), 894-903.

Alchian, A., and H. Demsetz (1972), "Production, Information Costs, and Economic Organization," American Economic Review, 62, 777-795.

Bartling, B., E. Fehr, M. A. Maréchal, and D. Schunk (2009): "Egalitarianism and Competitiveness," American Economic Review: Papers \& Proceedings, 99(2), 93-98.

Bolton, P., and M. Dewatripont (2005), "Contract Theory,” MIT Press Books.

Carpenter, J. P., P. Matthews, and J. Schirm (2010): "Tournaments and Office Politics: Evidence from a Real Effort Experiment," American Economic Review, 100, 504-517.

Charness, N. and Campbell, J.I.D. (1988). Acquiring skill at mental calculation in adulthood: a task decomposition. Journal of Experimental Psychology: General, 117, 115-129.

Charness, G., and P. Kuhn (2011): "Lab Labor: What Can Labor Economists Learn from the Lab?," in Handbook of Labor Economics, 4, ed. by O. Ashenfelter and D. Card. Elsevier, chapter 03, 229-330.

Charness, G., D. Masclet, and M. C. Villeval (2010): “Competitive Preferences and Status as an Incentive: Experimental Evidence," IZA Discussion Paper 5034, Bonn, and GATE WP 1016.

Charness, G., and M. C. Villeval (2009): "Cooperation and Competition in Intergenerational Experiments in the Field and Laboratory", American Economic Review, 99(3), 956-978.

Chase, W. G., \& Ericsson, K. A. (1982). Skill and working memory. In G. Bower (Ed.), The psychology of learning and motivation (Vol. 16, pp. 1-58). New York: Academic Press.

Corgnet, B., R. Hernan-Gonzalez, S. Rassenti (2011): "Real Effort, Real Leisure and Real-time Supervision: Incentives and Peer Pressure in Virtual Organizations", Working Papers 11-05 Chapman University Economic Science Institute.

Deci, E. L. (1971). Effects of externally mediated rewards on intrinsic motivation. Journal of Personality and Social Psychology, 18(1), 105.

Dickinson, D. (1999): “An Experimental Examination of Labor Supply and Work Intensities," Journal of Labor Economics, 17, 638-670.

Dickinson, D., and M. C. Villeval (2008): "Does Monitoring Decrease Work Effort?: The Complementarity Between Agency and Crowding-Out Theories," Games and Economic Behavior, 63, 56-76.

Dohmen, T., and A. Falk (2011): "Performance Pay and Multi-Dimensional Sorting: Productivity, Preferences and Gender,” American Economic Review, 101 (2), 556-590. 
Eriksson, T., A. Poulsen, and M. C. Villeval (2009): "Feedback and Incentives: Experimental Evidence," Labour Economics, 16 (6), 679-688.

Falk, A., and D. Huffman (2007): "Studying Labor Market Institutions in the Lab: Minimum Wages, Employment Protection, and Workfare," Journal of Institutional and Theoretical Economics, 163(1), 30-45.

Falk, A., and A. Ichino (2006): "Clean Evidence on Peer Effects," Journal of Labor Economics, 24, 39-58.

Gneezy, U., M. Niederle, and A. Rustichini (2003): "Performance in Competitive Environments: Gender Differences," Quarterly Journal of Economics, 118, 1049-1074.

Grosse, S., L. Putterman, and B. Rockenbach (2011): "Monitoring in Teams: A Model and Experiment on the Central Monitor Hypothesis," Journal of the European Economic Association, 9(4), 785-816.

Hamilton, B., J. Nickerson, and H. Owan (2003): “Team Incentives and Worker Heterogeneity: An Empirical Analysis of the Impact of Teams on Productivity and Participation," Journal of Political Economy, 111(3), 465-497.

Holmström, B. (1982): “Moral Hazard in Teams,” Bell Journal of Economics, 13, 324-340.

Jones, S., C. Johnson-Yale, S. Millermaier, and F. S. Perez (2009): "Everyday Life, Online: U.S. College Students' Use of the Internet," First Monday, 14(10),

Koepp MJ, Gunn RN, Lawrence AD, Cunningham VJ, Dagher A, Jones T, et al. (1998): "Evidence for striatal dopamine release during a video game," Nature, 393, 266-268.

Laffont, J. J., and D. Martimort (2002): The Theory of Incentives: The Principal-Agent Model. Princeton University Press: Princeton, N.J.; Oxford.

Lazear, E. P. (2000): "Performance Pay and Productivity," American Economic Review, 90(5), 1346-1361.

Ledyard, J. (1995): Public Goods: A Survey of Experimental Research, in Handbook of experimental economics, ed. by J. H. Kagel and A. E. Roth. Princeton: Princeton University Press, 111-94.

Lei, V., C. N. Noussair, and C. R. Plott (2001): "Nonspeculative Bubbles in Experimental Asset Markets: Lack of Common Knowledge of Rationality vs. Actual Irrationality," Econometrica, 69(4), 831-859.

Malachowski, D. (2005): "Wasted Time at Work Costing Companies Billions," San Francisco Chronicle, July 11: http://www.sfgate.com/cgi-bin/article.cgi?f=/g/a/2005/07/11/wastingtime.TMP

Mohnen, A., Pokorny, K., and D. Sliwka (2008): “Transparency, Inequity Aversion, and the Dynamics of Peer Pressure in Teams: Theory and Evidence," Journal of Labor Economics, 26, 693-720.

Montmarquette, C., J. Rulliere, M. C. Villeval, and R. Zeiliger (2004): "Redesigning Teams and Incentives in a Merger: An Experiment with Managers and Students," Management Science, 50, 1379-1389. 
Nalbantian, H., and A. Schotter (1997): "Productivity under Group Incentives: An Experimental Study," American Economic Review, 87(3), 314-341.

Niederle, M., and L. Vesterlund (2007): "Do Women Shy Away from Competition? Do Men Compete Too Much?," The Quarterly Journal of Economics, 3(8), 1067-1101.

Prendergast, C. (1999): "The Provision of Incentives in Firms," Journal of Economic Literature, $37(1), 7-63$.

Rutström, E., and M. Williams (2000): "Entitlements and Fairness: An Experimental Study of Distributive Preferences," Journal of Economic Behavior and Organization, 43(1), 75-89.

Swed, F., and C. Eisenhart (1943): "Tables for Testing Randomness of Grouping in a Sequence of Alternatives," Annals of Mathematical Statistics, 14, 66-87.

Smith, A. (2013): “Smartphone ownership update." Pew Research Center's Internet \& American Life Project. Accessed June 6th 2013 at http://pewinternet.org/Reports/2013/SmartphoneOwnership-2013.aspx

Tamir, Diana I., and Jason P. Mitchell: (2012) "Disclosing information about the self is intrinsically rewarding," Proceedings of the National Academy of Sciences, 109(21), 80388043.

Treadway, Michael T., et al. (2012): "Dopaminergic mechanisms of individual differences in human effort-based decision-making," The Journal of Neuroscience, 32(18), 6170-6176.

Van Dijk, F., J. Sonnemans, and F. van Winden (2001): "Incentive Systems in a Real Effort Experiment," European Economic Review, 45, 187-214.

Young, K.S (2005): "Internet Addiction Prevention and Education: Preventive Education Training Can Reduce Problematic Internet Use in the Workplace and Help Employers Create a Work Environment that Encourages Identification and Treatment of Addictive Online Behaviors," The Journal of Employee Assistance, 15(3), 15-19.

Young, K.S (2006): "The Internet and Workplace Transformation," Advances in Management Information Systems, 7, 193-204.

Zapata-Phelan, C. P., Colquitt, J. A., Scott, B. A., \& Livingston, B. (2009). "Procedural justice, interactional justice, and task performance: The mediating role of intrinsic motivation," Organizational Behavior and Human Decision Processes, 108(1), 93-105. 


\section{APPENDIX A}

We solve the model by maximizing the utility function of worker $i \in 1, \ldots, N$ with respect to work effort $e_{i}$ for each of the four treatments:

$$
\begin{array}{cc}
\max _{e_{i}} U_{i}:=s_{i} A{ }_{k=1}^{N . t .} & e_{k}-\alpha \frac{e_{i}^{2}}{2}-\beta \frac{1-l_{i}^{2}}{2} \\
& e_{i}+l_{i} \leq 1 \\
& e_{i}, l_{i} \geq 0
\end{array}
$$

Deriving first order conditions of [1], we obtain the equilibrium work effort for each treatment.

Internet effects:

- Under individual pay:

If $\alpha>A(\alpha \leq A$ and $\alpha+\beta>A)$, then the increase in production in the no Internet treatment compared with the Internet treatment is equal to $\frac{\beta A}{\alpha \alpha+\beta}\left(\frac{\alpha+\beta-A}{\alpha+\beta}\right)$ which is increasing in $\beta$ and decreasing in $\alpha$ (increasing in both $\alpha$ and $\beta$ ). If $\alpha+\beta \leq A$, we will observe no differences across treatments.

- Under team pay:

If $N \alpha>A(N \alpha \leq A$ and $N \alpha+\beta>A)$, then the increase in production in the no Internet treatment compared with the Internet treatment is equal to $\frac{\beta A}{N \alpha+\beta \alpha}\left(\frac{N \alpha+\beta-A}{N \alpha+\beta}\right)$ which is increasing in $\beta$ and decreasing in $\alpha$ (increasing in both $\alpha$ and $\beta$ ). If $N \alpha+\beta \leq A$, we will observe no differences across treatments.

Incentive effects:

- In the presence of Internet:

If $\alpha+\beta>A(\alpha+\beta \leq A$ and $N \alpha+\beta>A)$, then the increase in production under individual pay compared with team is equal to $\frac{N-1 A}{N \alpha+\beta}\left(\frac{N \alpha+\beta-A}{N \alpha+\beta}\right)$ which is decreasing (increasing) in both $\alpha$ and $\beta$. If $N \alpha+\beta \leq A$, we will observe no differences across treatments. 
- In the absence of Internet:

If $\alpha>A(\alpha \leq A$ and $N \alpha>A)$, then the increase in production under individual pay compared with team is equal to $\frac{N-1 A}{N \alpha}\left(\frac{N \alpha-A}{N \alpha}\right)$ which is decreasing (increasing) in $\alpha$. If $N \alpha \leq A$, we will observe no differences across treatments.

\section{APPENDIX B}

Table B1. - CLICKING TASK.

\begin{tabular}{|c|c|c|c|c|}
\hline & $\begin{array}{c}\text { INDIVIDUAL } \\
\text { PAY \& } \\
\text { NO INTERNET }\end{array}$ & $\begin{array}{c}\text { INDIVIDUAL PAY } \\
\& \\
\text { INTERNET }\end{array}$ & $\begin{array}{c}\text { TEAM PAY } \\
\& \\
\text { NO INTERNET }\end{array}$ & $\begin{array}{c}\text { TEAM PAY } \\
\& \\
\text { INTERNET }\end{array}$ \\
\hline Success rate & $97.8 \%$ & $98.2 \%$ & $98.7 \%$ & $97.0 \%$ \\
\hline \multicolumn{5}{|c|}{ Proportion tests (p-values) } \\
\hline $\begin{array}{l}\text { INDIVIDUAL PAY \& } \\
\text { INTERNET }\end{array}$ & .75 & - & - & - \\
\hline $\begin{array}{l}\text { TEAM PAY \& } \\
\text { NO INTERNET }\end{array}$ & .45 & .66 & - & - \\
\hline $\begin{array}{l}\text { TEAM PAY \& } \\
\text { INTERNET }\end{array}$ & .58 & .39 & .20 & - \\
\hline
\end{tabular}

Success rate: Average proportion of the 240 yellow boxes subjects had clicked before they disappeared from the screen.

Table B2. - INDIVIDUAL PRODUCTION.

Panel regressions coefficients with random effects and robust standard deviations for session clusters.

\begin{tabular}{|c|c|c|c|c|}
\hline & $\begin{array}{c}\text { INDIVIDUAL PAY } \\
\& \\
\text { NO INTERNET } \\
\end{array}$ & $\begin{array}{c}\text { INDIVIDUAL PAY } \\
\& \\
\text { INTERNET } \\
\end{array}$ & $\begin{array}{c}\text { TEAM PAY } \\
\& \\
\text { NO INTERNET } \\
\end{array}$ & $\begin{array}{c}\text { TEAM PAY } \\
\& \\
\text { INTERNET }\end{array}$ \\
\hline Intercept & $3.33 * * *$ & $3.42 * * *$ & $2.95 * * *$ & $2.62 * * *$ \\
\hline Period trend & $.53 * * *$ & $.34 * * *$ & $.32 * * *$ & $.17 * *$ \\
\hline
\end{tabular}




\section{APPENDIX C}

\section{INSTRUCTIONS (TEAM PAY \& INTERNET)}

Instructions for all treatments are available at:

https://sites.google.com/site/realleisureincentives/home/instructions

Note: In the no Internet treatments (INDIVIDUAL PAY \& NO INTERNET, TEAM PAY \& NO INTERNET), five slides regarding Internet browsing were removed.

\section{APPENDIX D}

We show that using the Internet was disruptive. For example, those subjects who switched back and forth between the Internet and the task were more likely to complete a table incorrectly. In Table D1, we show the results of a Probit regression where the dependent variable is a dummy that takes value one if the table was correctly solved, and zero otherwise. We first observe that the probability of correctly completing a table is lower when subjects have already completed more tables (Table number). We also control for the time that subjects spent to complete a table, discounted by the time they were on the Internet (Effective time), and observe that those who took more time to complete a table were more likely to make mistakes. In Regression 1 we also control for a dummy (Switching) that takes value 1 if the subject switched (at least once) to the Internet screen before completing the table. In Regression 2 we control for the time that subjects spent on the Internet (Time on Internet). In Regression 3 we control for both variables. We find that browsing the Internet as well as switching back and forth between the Internet and the task screens decreased the probability of completing a table correctly.

TABLE D1 - INTERNET BROWSING AND PRODUCTION ACCURACY

Probit regression of the probability of correctly completing a table with random effects and robust standard deviations for session clusters.

\begin{tabular}{lccc}
\hline \hline & Regression 1 & Regression 2 & Regression 3 \\
\hline Intercept & $.873^{* * *}$ & $.854^{* * * *}$ & $.879^{* * * *}$ \\
Period trend & $.070^{* * *}$ & $.072^{* * *}$ & $.070^{* * * *}$ \\
Table number & $-.023^{* * *}$ & $-.024^{* * *}$ & $-.024^{* * *}$ \\
Effective time & $-.106^{* * *}$ & $-.103^{* * *}$ & $-.107^{* * *}$ \\
Switching & $-.418^{* * *}$ & - & $-.297^{* * *}$ \\
Time on Internet & & $-.095^{* * *}$ & -.042 \\
Team Pay & .003 & -.003 & .003 \\
\hline Number of observations & 3601 & 3601 & 3601 \\
Wald test & 49.73 & 58.54 & 59.48 \\
Prob $>\chi^{2}$ & $<.001$ & $<.001$ & $<.001$ \\
\hline${ }^{*}$ p-value $<.10,{ }^{* *}$ p-value $<.05$, and ${ }^{* * *}$ p-value $<.01$ & & &
\end{tabular}


Finally, we did not find significant differences across treatments as the treatment dummy (Team Pay) was never significant (p's > .964) when included in any of the three regressions reported in Table D1. We also conducted similar regressions controlling for interaction effects between the treatment dummy and the variables "Switching" or "Time on Internet", but the coefficients were never significant (p's $>.270)$. 